\title{
EL MIEDO AL «CAMBIO INCONTROLABLE»: LA HORA FALLIDA DE FRAGA DURANTE LA TRANSICIÓN ESPAÑOLA
}

\author{
The Fear of a 'Change out of Control': \\ Fraga's Failed Turn during the Spanish Transition
}

\author{
JUAN MARÍA SÁNCHEZ-PRIETO \\ Universidad Pública de Navarra \\ juanm.sanchez@unavarra.es \\ GUILLERMO ZAFRA \\ Universidad Pública de Navarra \\ guillezafra@hotmail.com
}

Cómo citar/Citation

Sánchez-Prieto, J. M. y Zafra, G. (2016).

El miedo al «cambio incontrolable»: la hora fallida de Fraga

durante la Transición española.

Revista de Estudios Políticos, 174, 299-329.

doi: http://dx.doi.org/10.18042/cepc/rep.174.01

\section{Resumen}

La imagen de una Transición exitosa está unida en España a tres palabras clave: reformismo, centrismo y democracia, aunque los actores del momento no siempre coincidieran en su significado, ni tampoco en la actualidad los estudiosos convengan en las individualidades o grupos que los sostuvieron para promover el cambio político. En este artículo se profundiza en el papel de Fraga durante el tardofranquismo y primera fase de la Transición española, incidiendo en la imagen del pasado que incorpora su concepto y proyecto de reforma, lo que permite explicar mejor la presencia de Cánovas del Castillo y otros referentes históricos de la Restauración en el discurso y comportamiento político de Fraga a la salida de la dictadura franquista. Antes que manifestación de un deliberado uso político del pasado, esos referentes se antojan como un recurso que enmascara la propia indefinición de su proyecto, su desconexión con el cambio social o las dificultades en su relación con el rey, como razones principales de un fracaso en la hora más deseada de su trayectoria política, que no traducen sino el miedo de Fraga a un «cambio incontrolable». 


\section{Palabras clave}

Representación del pasado; reformismo; canovismo; cambio político; Fraga Iribarne, Manuel; Transición española.

\section{Abstract}

The image of a successful political transition is linked in Spain to three key words: reform, centrism and democracy. The political actors of that moment did not agree on their meaning, whilst scholars today do not agree on which political groups supported and promoted political change in Spain at that time. This paper analyses the role of Manuel Fraga Iribarne during the late stage of the Francoist Regime and the first stage of the Spanish Transition. It highlights the image of the past which characterised his project of political reform. This explains better the presence of Cánovas del Castillo and other historical references of the Restauración in Fraga's discourse and political behaviour. These references, more than being simply a manifestation of his political use of the past, unmask the lack of identity of his own political project, his disconnection from social change and the difficulties arising from his relationship with the King. These are argued to be the main reasons for his Fraga's defeat at precisely the moment he had coveted throughout his political career, revealing his fear of a "change out of control".

\section{Keywords}

Image of the past; reformism; canovism; political change; Manuel Fraga: Spanish Transition. 


\section{SUMARIO}

I. INTRODUCCIÓN. II. LA APUESTA REFORMISTA: FRAGA, TEÓRICO DEL CENTRO. 1. Campaña de conferencias. 2. ¿̇Fraga, precursor del centro?. III. LAS EXPECTATIVAS DE FRAGA Y EN TORNO A FRAGA DURANTE EL TARDOFRANQUISMO. 1. De la sobreexposición política... 2. ... al aparente desvanecimiento de Fraga. IV. LA HORA DE FRAGA EN EL PRIMER GOBIERNO DE LA MONARQUÍA. 1. Un nuevo Cánovas. 2. En busca de un Sagasta. V. LA RELACIÓN CON EL REY. 1. Las interferencias de Suárez y Fernández-Miranda. 2. Cambio de registro: de Cánovas a Maura. VI. EL DESENLACE: FRAGA Y LA IMAGEN DE LA «DERECHA SALVAJE». VII. A MODO DE CONCLUSIÓN. BIBLIOGRAFíA.

\section{INTRODUCCIÓN}

La imagen de una Transición exitosa está unida en España a tres conceptos clave: reformismo, centrismo y democracia, aunque los protagonistas del momento no siempre coincidieran en su significado, como tampoco hoy los estudiosos, algo que afecta particularmente a la figura de Manuel Fraga. Mateos y Soto distinguen desde los años sesenta dos grupos fundamentales: inmovilistas y aperturistas, a diferenciar estos últimos de los futuros reformistas, partidarios de una democracia plena. Fraga, con Arias Navarro, es contemplado a la muerte de Franco como un pseudoreformista. Palomares ha insistido en el papel fundamental de los reformistas para el triunfo de la democracia, pero difumina las fronteras entre aperturistas y reformistas, al igual que Powell. Los reformistas, identificados con la generación del príncipe Juan Carlos y de Adolfo Suárez, tendrían en el grupo democristiano Tácito su mejor exponente. Fraga, aunque pudiera calificarse de aperturista y pertenezca a una generación anterior, debe ser considerado — según Palomares- como el pionero entre los reformistas e incluso la cabeza de su causa y de un programa político centrista desde 1969, aunque experimentase tras la muerte de Franco un giro radical que le impidió convertirse en el líder de la España de la Transición ${ }^{1}$.

Mateos y Soto (2005: 93-95, 118-119); Palomares (2006: 29-35, 147-148, 280-289); Powell (2007: 50-53). El acento sobre Fraga como adelantado del centro se encuentra ya en Gilmour (1999: 73-102). Planteamiento inverso es el de Gallego (2008: 15, 695-720), que a la tesis de la continuidad e iniciativa del reformismo opone — enfatizando la personalidad y primer gobierno de Suárez — la tesis del control de 
Santos Juliá, corroborando otros trabajos, ha subrayado que los distintos proyectos reformistas de los sesenta no son sino manifestaciones de luchas de poder dentro del franquismo, con el objetivo no de fundamentar una ordenada transición a la democracia, sino de garantizar la continuidad del régimen. Aquellos políticos no sobrepasaban los ideales liberales decimonónicos y nadie como Fraga, a su juicio, expresaría mejor los límites de ese reformismo. Su originalidad habría sido la de tomarse por «un Cánovas redivivo» para concebir el futuro postfranquista como «autoritarismo seguido de turno pacífico». $\mathrm{Da}$ a entender que esa identificación de Fraga con Cánovas arrancaría cuanto menos de 1969, cuando sale derrotado del Gobierno y comienza a trazar su plan $^{2}$. Fuera de este momento, la tesis sobre Cánovas como referente histórico esencial de la derecha española ha sido establecida por Piqueras ${ }^{3}$.

En este artículo se pretende profundizar en el perfil y actuación política de Fraga durante el tardofranquismo y la Transición, incidiendo en el primer Gobierno de la Monarquía, que vino a constituir la hora fallida de Fraga y de su idea reformista. No basta atribuir el éxito final del reformismo a Suárez, como hace Palomares, sin contrastar la segunda reforma con la experiencia reformista de la primera fase de la Transición, mucho menos estudiada, según ha puesto de relieve Sánchez-Cuenca ${ }^{4}$, y sin explicar las razones de este fracaso, que afectó mucho más a Fraga que a Arias ${ }^{5}$. En este sentido, se considera necesario analizar y valorar con mayor detenimiento la imagen del pasado que incorpora el concepto y proyecto fraguista de reforma, lo que permitirá

un proceso no deseado, que nunca se habría llevado a cabo sin mediar la movilización democrática de la oposición.

2 Hispán (2006); Juliá (2010: 236-237, 265-268). La crítica de Juliá a Fraga aleja paradójicamente a Suárez del polo reformista al subrayar excesivamente la novedad de su planteamiento, en contraste con el enfoque mencionado de Gallego.

3 De Fraga a Aznar, mostraría así un continuo déficit democrático (Piqueras, 2008). Reformulando esa tesis en positivo, Penella (2009: 190-191) retrotrae a 1956 la convicción liberal conservadora de Fraga y el estímulo de Cánovas como referente histórico, aunque no lo justifica.

4 Sánchez-Cuenca (2014: 16, 31).

5 Sánchez-Cuenca (2014: 25, 154-158), criticando los simples juicios retrospectivos, ha cuestionado la idea del fracaso del proyecto de Arias, preguntándose por situaciones contrafácticas de haber continuado este al frente del Gobierno, ya que el cese según el autor remitiría a otras causas principales. Aunque pueda discutirse la tesis, ese contrapunto invita entonces a centrar mucho más la atención en la figura de Fraga que en la de Arias, a la hora de evaluar las posibilidades y límites del reformismo de la primera fase de la Transición. 
explicar mejor la presencia de Cánovas del Castillo y otros referentes históricos de la Restauración en el discurso y quehacer políticos de Fraga.

La hipótesis que se plantea en este estudio es hasta qué punto esas invocaciones históricas son manifestación de un mantenido y deliberado uso político del pasado, al servicio de una idea madurada en el tiempo, por parte de Fraga; o resultan más bien un recurso sobrevenido —en la celebración del centenario de la Restauración y de la Constitución de 1876- que sirve para cubrir la propia indefinición de su proyecto, su desconexión con el cambio social o las dificultades de su relación con el rey: esto es, las razones principales de un fracaso, con la correspondiente decepción personal, que no traducen - en el momento más acariciado de su trayectoria política- sino el miedo de Fraga a un cambio incontrolable ${ }^{6}$.

\section{LA APUESTA REFORMISTA: FRAGA, TEÓRICO DEL CENTRO}

La nueva apuesta política de Fraga comienza, en efecto, en 1969. Fraga había entrado en el Gobierno de 1962, pronto calificado de aperturista y reformista. Proveniente del equipo de Ruiz Jiménez en Educación, Fraga pasó al Instituto de Estudios Políticos, donde comenzó a esbozar un proyecto de reforma de las Leyes Fundamentales. Responsable del centro en 1961, buscó orientarlo a las nacientes ciencias sociales ${ }^{7}$. Al frente del Ministerio de Información, creó el Instituto de Opinión Pública y fue artífice de la Ley de Prensa de 1966, que dio a Fraga una indiscutible posición dentro de aquel Gobierno: fue la primera gran reforma política del país ${ }^{8}$. Fraga quiso desde el principio intervenir en la batalla por la institucionalización del régimen, aunque su proyecto de 1963 fue relegado por Franco, priorizando las ideas de Carrero Blanco y López Rodó, que fructificaron en la Ley Orgánica del Estado (1966-1967)9.

Entre el frente Fraga-Solís-Castiella, que pretende reforzar la Organización Sindical y la estructura del Movimiento con un proyecto de Ley de Asociaciones, y el liderado por Carrero-López Rodó para coronar el régimen, se situó —intentando mediar entre las dos facciones- Herrero Tejedor,

6 Desde el punto de vista metodológico, el estudio sigue las pautas tradicionales de la historia intelectual, en diálogo con la evolución política del periodo comprendido, considerando como fuentes primarias los propios textos de Fraga, y como secundarias y de manera selectiva la prensa, además de realizar una revisión crítica de la bibliografía actual.

7 Iglesias de Ussel (2012: 159-161); Elorriaga (2014: 30-32).

8 Cebrián (1980: 105-107).

9 Hispán (2006: 319-324, 350-351, 405-427). 
vicesecretario general del Movimiento con Adolfo Suárez como jefe de gabinete $^{10}$. Nombrado Carrero vicepresidente del Gobierno en 1967, el incremento de las tensiones condujo a la crisis de 1969, el escándalo Matesa actuando de detonador. La ofensiva de los políticos contra los tecnócratas se saldó paradójicamente con la derrota de Solís y Fraga, y en el momento en que el príncipe Juan Carlos acababa de ser designado sucesor de Franco, lo que fue considerado también como una victoria de Carrero ${ }^{11}$. Con la salida de Fraga del Gobierno, Suárez ocupó la dirección general de TVE para desde ahí popularizar la imagen del futuro Rey ${ }^{12}$.

En su despedida de 1969, Fraga se presenta como un «hombre de Estado», sin servidumbres de grupo, guiado por un solo principio: «la España de la paz debe institucionalizarse equidistante de todo inmovilismo y de toda aventura». Una idea sobre la que luego construirá su teoría del centro, apostando por «una política de evolución prudente, pero sin pausas, en todos los frentes», que introduce también ahora ${ }^{13}$. Fraga se estrena en su nuevo papel de outsider con motivo del debate de asociaciones, denunciando las maniobras del nuevo ministro del Movimiento, Torcuato Fernández-Miranda. Ante el pleno del Consejo Nacional, Fraga apuntaba a un futuro sin Franco, «un futuro político de ancha base, de prudencia y moderación», erigiéndose en defensor de «una política de centro, abierta y decidida, que nos saque de los viejos bandazos tradicionales, de la derecha a la extrema izquierda». Las asociaciones eran el instrumento necesario para lograr la «integración de las nuevas generaciones y de las nuevas clases, esas juventudes de la edad y el desarrollo que hoy están extramuros del sistema» ${ }^{14}$.

Más allá del alcance y significado de su discurso, la frustración que manifiesta Fraga como consecuencia de su derrota ante los tecnócratas, y la misma presencia interpuesta de Fernández-Miranda, guardan paralelismo con la experiencia que vivirá a su salida en 1976 del primer Gobierno de la Monarquía.

\section{CAMPAÑA DE CONFERENCIAS}

Fraga emprende una campaña de conferencias por la geografía española divulgando su pensamiento y su particular «Teoría del centro», título de una

\footnotetext{
10 Morán (1979: 138-141); Herrero (2007: 48-49); Fuentes (2011: 53-54, 95).

11 Hispán (2006: 543-544, 549-551, 558-561, 587-615).

12 Morán (1979: 207-215); Abella (2006: 32-34, 46-48); Herrero (2007: 42-43, 49$50)$.

13 Discurso de 29/10/1969, en Milián (1975: 249-251).

14 Discurso de 15/12/1969, en Fraga (1972: 267-274).
} 
de ellas (marzo de 1972), entre otras particularmente señaladas: «El desarrollo político» (febrero de 1971), "Cambio social y reforma política», «La Monarquía como forma de Estado» (noviembre de 1971) o «Panorama político de la España actual» (junio de 1972). El eco de estas intervenciones en la prensa manifiesta su propio deseo de abrir un espacio de discusión ${ }^{15}$. Su salto al ruedo lo califica él mismo como un ejercicio de oposición "dentro del sistema» que entiende "legítima» $\mathrm{y}$ "leal», porque es lo que «España necesita y se merece» ${ }^{16}$. La capacidad de convocatoria de Fraga para «hablar de política sin utilizar el incensario» llamó la atención: "cada día son más los españoles que están esperando que pase algo, y no ven que ellos puedan provocar ningún cambio, ni puedan participar, y ni siquiera les dejen ser espectadores», resumía un observador $^{17}$. La irrupción de Fraga lanzó la opinión publicada entre 1971 y 1973 a una pequeña guerra de medios ${ }^{18}$, a un lado los diarios Pueblo y Arriba, enfrente $A B C, Y a$ e Informaciones, que no representó sino una nueva batalla en la lucha de poder mantenida por las familias franquistas.

La actividad de Fraga acaba resultando molesta. En otoño de 1971, es excluido del Consejo del Movimiento y apartado de las Cortes. Cuando Fraga pronuncia su "Teoría del centro»" ${ }^{19}$ ante un auditorio repleto, la expectación es enorme. El examen del debate europeo - el anunciado final de las ideologías, la presunta superación del liberalismo por un conservadurismo emergente, el surgimiento de la nueva izquierda y el anquilosamiento de los viejos partidos- le llevaba a una conclusión: el predominio de las políticas de centro en todas partes, Estados Unidos, Francia, Italia. Fraga enfatizó una concepción del centro como actitud, como un modo de hacer política «realista, solvente, reformista", por lo que admitía una inmediata traducción a la realidad española, en pleno debate sobre la posible evolución del régimen. «El orden establecido no se rechaza, pero tampoco se acepta incondicionalmente; el centrista desea transformarlo selectivamente y evolutivamente, es decir, de modo progresivo y sin violencia». Asociado a moderación, la fuerza del centro residía en su capacidad de conectar con las aspiraciones de los españoles. Para ello había que «asumir, pura y simplemente, la realidad social», dejar a España expresarse "rompiendo el diálogo ficticio entre unos ultras tolerados y unos ultras clandestinos», afirma.

15 Fraga (1980: 277, 286).

$16 Y a, 03 / 04 / 1971$.

17 Ramón Pi, Tele/Exprés, 23/02/1971.

18 Jiménez Blanco (1978: 189).

19 "Teoría del centro", conferencia pronunciada en el Club Mundo de Barcelona, 10/03/1972, ampliada en Fraga (1973: 213-257). 
Fraga entiende que las clases medias en expansión son el auténtico soporte sociológico del centro. El anhelo compartido de tranquilidad social no podía ocultar que los españoles «están ahí, y cualquier día tendrán que opinar, o que votar». Fraga no aclara los términos del diálogo con una sociedad a la que se dirige con cierto paternalismo, y si podría afectar a los excluidos del sistema. Pero el desdén con que se refiere a «la actitud irresponsable intelectualmente de cierta gauche divine, y su total inanidad práctica», que no le inspira "más que desprecio y risa», constriñe mucho su voluntad dialogante. Fraga parece buscar un único interlocutor para aquel discurso de centro: la propia clase política del franquismo. «En la actualidad, estamos demasiado desplazados a la derecha. Si queremos evitar un posible bandazo a la izquierda, debemos marchar hacia el centro, por el camino de las reformas ${ }^{20}$. Se trataba simplemente, por el momento, de aislar a los extremos para asegurar la propia vigencia del régimen.

La teoría del centro de Fraga acaba sugiriendo una nueva fórmula doctrinaria que definirá a partir de ahora toda su actuación política: clases medias + politica de centro = reforma. . Hay que notar que, en este discurso, Fraga hace una mención genérica a los moderados del siglo XIX y a Narváez, pero no a Cánovas. Tampoco se encuentra esa referencia en ninguna otra de las conferencias pronunciadas en este tiempo.

\section{2. ¿̇FRAGA, PRECURSOR DEL CENTRO?}

Barcelona, Salamanca, Valencia... Fraga se convierte en 1972 en el apóstol del centro: un centro «prudente y tolerante, reformista declarado, pero sin la ingenuidad de progresistas y conservadores», para potenciar «un gran consenso nacional», predica ${ }^{21}$. Pero ¿̨ue Fraga realmente el precursor del centro? Aunque Fraga se otorgue el mérito, no fue el primero en introducir el concepto en el debate español de la época. Antes de 1969, Calvo Serer y el diario Madrid habían extendido el término ${ }^{22}$. Ligado a Don Juan de Borbón, aquel ya había ubicado el centro político "a la derecha de la oposición fuera del Régimen», considerando preferible «la evolución gradual por la vía reformista

20 Fraga (1973: 241, 243, 250, 255 y 257). Para Gilmour (1999: 98-99), la llamada de Fraga a una política de centro se asemeja al concepto original de falangismo joseantoniano, aunque atendiendo a otros términos presentes en su discurso como centro moderado, normal evolución o armonía con Europa presume que Fraga está contemplando el retorno de España al orden liberal occidental dominante.

21 Abc, 11/05/1972; Informaciones, 27/05/1972.

22 Palomares (2006: 166-167). 
que representa el centro», a cualquier «irrupción violenta de un proceso revolucionario» o extremismo democrático como fórmula de salida de la dictadura. El centro acepta la legalidad del Régimen con ánimo de transformarla, adecuándola a la «realidad cambiante», pero Calvo es mucho más claro que Fraga al señalar como característica propia del centro político la aspiración de que «gran parte o todos de los que están fuera del Régimen puedan participar en la vida política con la plenitud e igualdad de derechos públicos». En el caso español, anticipaba finalmente Calvo Serer, «el centro puede ser la base de una coalición o formación mayoritaria desde el momento en que puede agrupar a los sectores izquierdistas de la derecha y a los derechistas de la izquierda ${ }^{23}$.

Aunque Fraga se quejase más tarde de que Suárez le había robado el centro, fue Fraga primero quien se apropió y adaptó a su conveniencia las ideas de otros, que a su vez le consideraron su detractor. Resulta paradójico que en plena campaña fraguista del centro, se produzca el cierre definitivo del diario Madrid, víctima de la Ley Fraga. Como también lo será que el primer mentor del centro político reformista, Calvo Serer, acabe en 1974 propugnando la opción rupturista junto a Carrillo en la Junta Democrática ${ }^{24}$.

\section{LAS EXPECTATIVAS DE FRAGA Y EN TORNO A FRAGA DURANTE EL TARDOFRANQUISMO}

Si desde 1973 todo el mundo quiso presentarse como reformista ${ }^{25}$, durante ese mismo año «ya casi nadie duda del protagonismo de Manuel Fraga en la política española», asevera un colaborador suyo ${ }^{26}$. Fue un efecto buscado. De 1970 data el primer círculo fraguista, en el origen del Club Agora de Barcelona, confluyente luego en GODSA: un gabinete de estudios destinado a la formación de un grupo político si finalmente se autorizaban las asociaciones. Registrado en 1974, el grupo estaba ya constituido antes del destino londinense de Fraga ${ }^{27}$, pudiendo esgrimir el libro Legitimidad y representación (recopilación de las conferencias de Fraga) como referente ideológico. Fraga se

23 Calvo Serer (1968: 314-317). Véase también el recorrido realizado por los países occidentales - como hará Fraga en 1972 - para hacer valer las posiciones de centro (pp. 256-259).

24 Díaz y Meer (2010).

25 Juliá (2010: 236).

26 Milián (1975: 295).

27 Milián (1975: 281-282); Fraga (1980: 297); Penella (2005: 43 y ss.); Palomares (2006: 169, 197-200, 347). Juliá resta importancia a GODSA como embrión de un partido. 
adelantó al grupo Tácito, creado en esa misma primavera de 1973, y manifestó una clara ambición política ${ }^{28}$. El protagonismo de Fraga en 1973 condujo a que su nombre apareciera en la terna donde salió elegido Carrero presidente de Gobierno.

Emilio Romero calificó de sorpresa esa inclusión, y que no hubiera figurado en ella Torcuato Fernández-Miranda, el verdadero intérprete a su juicio de Franco y Carrero ${ }^{29}$, de hecho nombrado vicepresidente a continuación. La marcha de Fraga a la Embajada de Londres contentó a sus oponentes y al propio Fraga, que consideró que su posición como número dos en aquella terna hacía necesaria la distancia: «no quería aparecer criticando todos los días al recién nombrado Jefe de Gobierno», dirá en 1975. Había que preservar su imagen de hombre del futuro español, que comenzó a labrarle la prensa ${ }^{30}$. Lo que no podía prever Fraga era el asesinato de Carrero apenas dos meses después. Fraga figuraba el primero entre los presidenciables ante la audiencia informada ${ }^{31}$, pero esa posibilidad de alternativa a Carrero en la que confió se había diluido con rapidez ${ }^{32}$. Ni siquiera figuró en la nueva terna, como tampoco Nieto Antúnez ni Torcuato, los auténticos derrotados con la elección de Arias Navarro ${ }^{33}$.

\section{DE LA SOBREEXPOSICIÓN POLÍTICA...}

Fraga permaneció en Londres pero no renunció a su campaña política, buscando una mayor sintonía con la opinión pública. Sus libros adquieren un nuevo aire popular, como reflejan La República y Las Leyes ${ }^{34}$, recreación de los diálogos platónicos, con numerosas ediciones e ilustraciones de Mingote, en un claro afán divulgador, que convierte esas publicaciones no ya en una invitación programática, sino en un "auténtico catecismo del centro fraguista» ${ }^{35}$. Contaba además con una pequeña maquinaria (sus equipos, GODSA) para preparar sus idas y venidas de Londres, anunciadas y comentadas por los

28 Incluida la creación de un periódico independiente, proyecto que fraguaría en 1976 con El País, volviéndose contra las aspiraciones de Fraga (Fraga, 1980: 280, 327; Bernáldez, 1985: 134-137, 146, 199).

29 El Noticiero Universal, 10/10/1973.

30 Milián (1975: 321-323). «Soy un hombre del sistema y ahora juego un nuevo papel», afirmó Fraga tras su nombramiento como embajador (Informaciones, 17/09/1973).

31 Romero (1973: 201-202).

32 Bernáldez (1985: 123-125, 144-145).

33 Pueblo, 31/12/1973.

34 Fraga (1973b; 1975).

35 Informaciones, 7/06/1975. 
medios de comunicación, jugando Fraga con la idea de su peculiar exilio. Había creado asimismo los Premios de Periodismo Manuel Fraga (y toda una atmósfera alrededor de ellos: convocatoria, entrega de galardones) para favorecer la propia atención sobre su persona y su papel en la esfera pública del tardofranquismo.

A las apariciones programadas se añaden las generadas por la propia dinámica del espiritu del 12 de febrero. La llamada Operación Fraga se remonta a la elaboración misma del famoso discurso de Arias, donde trabajaron hombres de Fraga (Gabriel Cisneros, Pío Cabanillas) ${ }^{36}$, aunque pronto desconfiaron de que el presidente quisiera abrir realmente el régimen. La destitución del ministro Cabanillas, siguiendo los pasos de Fraga, fue la primera prueba, todavía quedaba el test de las asociaciones. En la entrega de los primeros premios periodísticos (diciembre de 1974), Fraga se comporta «en plan presidente de Gobierno» ${ }^{37}$ y se presenta a sí mismo como el hombre que se necesita, pero sin mayor definición, aunque la ocasión lo requería. Ante la idea de una Triple Alianza entre Fraga, Areilza y Silva, en crescendo cuando se acaba de tramitar el Estatuto de Asociaciones y se especula con la formación de una gran asociación política de carácter reformista por la que están interesados tanto Arias como el Príncipe ${ }^{38}$, Fraga es visto como la «vedette política» de ese hipotético «triunvirato centrista», y mantiene el suspense ${ }^{39}$. El desenlace del drama del centro se producirá durante la Transición, pero cabe establecer una cierta continuidad en la actuación política de Fraga desde este episodio de los Tres Mosqueteros al de los Siete Magnificos de la futura Alianza Popular, segunda versión de la operación Fraga.

Apenas un año después del discurso de Arias, la operación Fraga es vista ya como un fracaso. El programa del 12 de febrero, en su intento de pasar de un régimen de adhesión a uno de participación limitada, fue recortado por la burocracia franquista planteando una batalla contra el tiempo que cerraba las esperanzas de crear una inercia democratizadora desde las posiciones reformistas. El test de las asociaciones se convirtió en el test de Fraga. La contradicción de fondo del triángulo Silva-Fraga-Areilza se resolvió con la exclusión del primero (más próximo de Carrero que de Fraga hasta hacía poco) y el inicio del diálogo de Fraga con Tácito y el grupo de Fernández Ordóñez, que exigían la

36 Fallecido Cabanillas, Cisneros se atribuyó la autoría en exclusiva (Palomares, 2006: 349).

37 López Rodó (1993: 96).

38 Palomares (2006: 216-222); Gallego (2008: 109-114).

$39 A b c, 24 / 01 / 1975$. 
adopción en un programa común de conceptos liberales y democráticos ${ }^{40}$. Si algunos habían visto en Fraga una figura salvadora del régimen, los nuevos aliados potenciales lo convertían en una amenaza. «Fraga tiene ante sí la opción entre una versión asociacionista plenamente intrarrégimen o bien otra de cambio y de más largo alcance», valoró con lucidez Guillermo Medina, más tarde diputado de $\mathrm{UCD}^{41}$. Optando por lo segundo, siempre podría decirse que Fraga había intentado acogerse al asociacionismo franquista para reformarlo democráticamente, con independencia de que el régimen lo admitiese, pero estaba por ver su apuesta personal.

La indefinición de Fraga fue la razón principal de su fracaso. Algo parecido le sucederá durante la primera fase de la Transición. De la Cierva, próximo a él, lo consideró desde la metáfora teatral. La sobreactuación de Fraga fue un «serio error político», pues «no pudo soportar el desgaste de toda una expectación nacional centrada obsesivamente en él, y sin recibir nunca de él, en directo, una satisfacción política suficiente». Sin negar sus cualidades, Fraga acababa decepcionando en sus apariciones. De «comedia de errores» tildaba el «montaje espectacular» de su retorno discontinuo de Londres, atraído por los cantos de sirena del sistema, y algo más importante: «el error más grave de toda la operación, los bastidores, la pérdida de cara respecto del público» ${ }^{42}$.

\section{2. ... AL APARENTE DESVANECIMIENTO DE FRAGA}

Inverosímil y desenvuelta en gran parte entre bambalinas, la Operación Fraga se desvaneció. Fraga había pulsado opiniones en Londres, Barcelona o Madrid reuniéndose con Nieto Antúnez, Osorio, el Príncipe, Tierno Galván, el presidente Arias, López Rodó o Marcelino Oreja, además de Areilza y Fernández Ordóñez. El debate acerca de la viabilidad del Estatuto de Asociaciones provocó finalmente la ruptura del grupo Tácito ${ }^{43}$. Una facción (Osorio) se alineó con Silva en la aceptación del Estatuto ${ }^{44}$, mientras otra (Oreja) abogaba por fórmulas democráticas participando en el verano de 1975 en la creación

40 Areilza, por su parte, fue elaborando a lo largo de 1975 lo que llamó Operación Tránsito, diseñada a la medida de su propia ambición (Fuentes, 2011: 120-122).

41 Informaciones, 12/02/1975.

42 Gaceta Ilustrada, 23/03/1975. A la teatralización de la política se refirió Fraga poco después, en la presentación de la semblanza sobre su persona realizada por Milián, haciendo considerar que «la vida pública tiene algo de representación de determinados papeles y, por ello, justamente la representación es la idea clave en política, como en teatro" (Ya, 28/08/1975).

43 Powell (2007: 70-71); Gallego (2008: 122-127).

44 Informaciones, 13/03/1975. Abc, 8/05/1975. 
de FEDISA, club político al margen del Estatuto adonde remiten los orígenes de UCD. Fraga se quedó solo, aunque figuró en los inicios de FEDISA para no perder pie y para intentar hacer de ella —en connivencia con Solís- una asociación similar a la fallida triple alianz $a^{45}$. Fue abandonado incluso por Cabanillas, mediador en su primer acercamiento a los grupos de Oreja y Fernández Ordóñez.

Aparentemente Fraga se distanciaba del régimen del Estatuto, pero sin alinearse de verdad con quienes propugnaban abiertamente principios democráticos. Fraga apuesta por el trabajo en solitario con GODSA, sin resultados inmediatos. A diferencia de Fraga, aunque sin el mismo grado de visibilidad y compromiso, Suárez arriesgó implicándose en una asociación franquista. Estuvo en todos los pasos constitutivos de Unión del Pueblo Español (UDPE), promovida por el Gobierno para salvar el Estatuto, y pasó a encabezarla cuando falleció su mentor, Herrero Tejedor. Pudo así tejer una amplia red de relaciones dentro del Movimiento, lo que constituiría una ventaja estratégica en el futuro inmediato, inevitablemente democrático en su mente ya entonces ${ }^{46}$.

Con todo, Fraga seguía confiando en sus posibilidades y en las encuestas, que le otorgaban en 1975 el índice más alto de popularidad ${ }^{47}$. Fuera se le señalaba como el "potencial canalizador de la transición posfranquista» ${ }^{48}$ y durante los últimos meses de la enfermedad de Franco se había preocupado de divulgar dentro su programa político ${ }^{49}$. El retrato del gobernante -en tres tiempos, a la espera del cuarto— - se adelantó como una obra de servicio

$45 A b c, 11 / 04$ y 29/04/1975. Informaciones, 3/05 y 30/08/1975. El comunicado de FEDISA, firmado por Fraga, hablaba de reforma como «el paso de un sistema autoritario a otro democrático» (no en sentido de evolución dentro del Régimen) y excluía cualquier intención de constituir una asociación política dentro del Estatuto, lo que parecía disipar las dudas sobre su posición personal. Pero todavía en el otoño de 1975, Fraga se reunía con el ministro Solís reiterándole su disposición y —en su nombre- la de FEDISA a participar en una asociación política bajo el Estatuto. Para Palomares (2006: 219, 229-230, 253) el hilo fundamental es la voluntad de Fraga de constituir una asociación "progresista», que iría de la triple alianza a la creación de Reforma Democrática en febrero-marzo de 1976.

46 Abella (2006: 68-70); Palomares (2006: 224); Herrero (2007: 82-83, 95-100).

47 La Vanguardia, 5/04/1975. Más sondeos desde 1972 en Milián (1975: 315, 342, 356, 384-385).

48 Conferencia londinense de Stanley Payne, Informaciones, 3/06/1975. The Observer habló de Fraga como presidente de Gobierno con el rey Juan Carlos (Abc, 18/11/1975).

49 Serie de artículos de $A b c$ recopilados en Un objetivo nacional (Fraga, 1976), cuya presentación coincidió con la entrega de los segundos premios Manuel Fraga (Informaciones, 5/12/1975). 
militante ${ }^{50}$. Cuando falleció el dictador, Fraga creía sinceramente que podía convertirse en el próximo presidente de Gobierno. El mismo 20 de noviembre trasladó al príncipe Juan Carlos una nota defendiendo la idea de reforma y la necesidad de un fuerte liderazgo para acometerla ${ }^{51}$. La nueva entrega de los premios Manuel Fraga tenía seguramente más de una finalidad: al día siguiente, el Rey confirmaba a Arias Navarro.

\section{LA HORA DE FRAGA EN EL PRIMER GOBIERNO DE LA MONARQUÍA}

Cuando el Rey situó a su hombre de confianza, Fernández-Miranda, al frente de dos instituciones claves (Cortes y Consejo del Reino), Fraga se limitó a declarar que lo haría bien... ${ }^{52}$. Él aspiraba a más, pero su decepción por la renovación de Arias no le impidió entrar en el nuevo Gobierno ${ }^{53}$, en cuya remodelación intervino el monarca, forcejeando con el presidente. Arias perdía peones y se incorporaban aperturistas o reformistas reconocidos como Fraga, Areilza, Osorio o incluso Solís. También otros hombres jóvenes, educados en los patios interiores del franquismo, y que pasaron más desapercibidos, como Suárez, Calvo Sotelo y Martín Villa. Fraga fue visto como el hombre fuerte del gabinete y realmente lo era, uniendo al Ministerio de Gobernación las funciones de vicepresidente. El primer Gobierno de la Monarquía fue la hora de Fraga, la gran oportunidad de Fraga para hacer valer su idea de Reforma, pese al inconveniente de la presencia de Arias.

Pronto se vio la naturaleza contradictoria del nuevo Gobierno. Arias se presentó ante las Cortes (28 de enero de 1976) como un hombre consumido interiormente por sus dudas de lealtad a Franco. Buscando contrarrestar esa imagen negativa, Fraga realizó unas declaraciones a la prensa extranjera trasladando que era él como vicepresidente político quien debía asumir el peso y la dirección del proceso de reforma ${ }^{54}$. De hecho, y como si del mismo presidente se tratara, había presentado ya al Gobierno un esquema del proyecto con dos ejes principales. El primero, el establecimiento de un régimen parlamentario

50 Valoración del libro de Milián, Informaciones, 6/09/1975.

51 Bernáldez (1985: 153-154).

52 Informaciones, 5/12/1975.

53 Cernuda (1997: 118-122).

54 Entrevista en The Times, difundida por Cambio 16, 9-15/02/1976. Véase también la conferencia "Continuidad y reforma» (Club Siglo xxi, 2/02/1976; Fraga, 1976b: 149$166)$, donde quiso clarificar su proyecto de convivencia. 
reformando la legalidad vigente. Se trataba de convertir las Cortes franquistas en un sistema bicameral. El Congreso (con trescientos procuradores o «representantes de la familia») sería elegido por sufragio universal, mientras que para el Senado combinaba un sistema de elección parcial (entre candidatos propuestos por diputaciones provinciales, cabildos, ayuntamientos, órganos sindicales, corporaciones profesionales y otras instituciones) con la permanencia de cuarenta senadores vitalicios y la presencia de otros veinticinco designados por el rey. Las elecciones de ambas cámaras, con una nueva ley electoral para el Congreso y otra especial para el Senado, se preveían para junio de 1977. La segunda gran cuestión era la legalización de los partidos políticos, con una revisión legal de las asociaciones y la modificación de los artículos correspondientes del Código Penal.

El proyecto fraguista comprendía también el desarrollo de algunos derechos individuales, el anuncio de una amnistía y una política regional de carácter descentralizador. Elecciones, sufragio universal, cámaras representativas, libertades de asociación y reunión, partidos politicos, sensibilidad hacia las reivindicaciones autonomistas, amnistía... Pudo pensarse que la reforma llevaba al país hacia una democracia plena. Pero esta reforma gradual de algunas leyes fundamentales no conducía realmente a una realidad jurídica distinta de la franquista, aunque preveía que la cámara elegida pudiese determinar luego el alcance de las reformas. La mente de Fraga, hasta el último día de su mandato, fue clara: «lograda la reforma política habrá que enterrar por un tiempo las polémicas constitucionales y concentrarse en las acciones concretas de legislación y administración $»^{55}$. La aprobación de los partidos estaría supeditada además a la aceptación de las reglas fijadas por el Gobierno. Finalmente, el nuevo Gobierno tras las elecciones no debía surgir necesariamente del equilibrio de fuerzas parlamentarias: sería designado por el rey a propuesta del Consejo del Reino, negándose la virtualidad última del sufragio universal (condicionado ya por la existencia de una segunda cámara que podía actuar como válvula de seguridad frente a un resultado electoral imprevisto). La reforma respondía a un esquema excesivamente rígido, que invitaba a la confusión, y se hacía una identificación entre parlamentarismo formal y democracia, que nunca llegó a explicarse. A diferencia de Fraga, y a la vista de su misma indefinición y ambigüedad, Suárez no pretendió una multiplicación de leyes de la reforma que más tarde pudieran concretarse en una nueva recopilación de

55 Abc, 2/07/1976. Entrevista de Pilar Urbano, en Fraga (1976b: 275-293). Fraga defenderá después la metodología elegida de "tomar los asuntos uno a uno" desde su visión de la historia del constitucionalismo español como una sucesión de textos fundamentales fracasados (Fraga, 1987: 55). 
Leyes Fundamentales, sino una Ley para la Reforma que facilitara en el plazo más breve la elaboración de una nueva Constitución.

$\mathrm{Al}$ margen de estas dudas, fuesen doctrinales o motivadas por una excesiva prudencia, lo que restó a Fraga gran parte de su crédito reformista fue su dificultad para enfrentarse a situaciones de conflictividad social. En momentos decisivos o de crisis, cuando la actuación política debe trascender las simples reglas comunes, Fraga falla y como si le dominara el miedo hasta tiende a huir de la primera línea. Las primeras huelgas de 1976, los sucesos de Vitoria, la detención de los principales dirigentes de la oposición democrática, los acontecimientos de Montejurra ${ }^{56}$ : como ministro de Gobernación Fraga se vio absolutamente desbordado. La opinión acabó identificando el conflicto y la represión con el propio carácter autoritario de Fraga, contrariamente al arquetipo humano (tolerancia y moderación) determinado en 1971-1972. El gran beneficiado de esta situación fue Suárez, demostrando capacidad de reacción y gestión en circunstancias difíciles, al asumir las funciones del ministro responsable desaparecido ${ }^{57}$. El desgaste de Fraga fue enorme: «estuvo a prueba hasta mi salud de hierro», recordará después. Ante su "dramática soledad», se planteó con urgencia la necesidad de hacer balance ${ }^{58}$.

\section{UN NUEVO CÁNOVAS}

Lo hizo el 2 de junio de 1976, con ocasión del centenario de la Constitución de 1876. El ministro pronunció entonces una de sus más célebres conferencias, "Cánovas o el compromiso de la reconciliación" ", que invita a la

56 El análisis de todos esos hechos en Bernáldez (1985: 170-181) y Gallego (2008: 359$372,395)$.

57 Palomares (2006: 253-256) califica de errores de cálculo algunas de las actuaciones de Fraga, ausente de España al producirse los sucesos de Vitoria y Montejurra. Para Luca (2001: 19-24), por el contrario, esos sucesos se entienden como un auténtico intento de golpe de Estado orquestado por el propio Fraga, cuya intención era explotar el malestar social para desprenderse de adversarios políticos prodemócratas como Suárez, sobre quién pretendía hacer recaer las responsabilidades políticas de la represión, y forzar así la declaración del estado de excepción.

58 Fraga (1987: 53).

59 En Fraga (1976b: 7-30). A este texto se han referido López Nieto (1988: 15-16), Gilmour (1999: 131-132) y Piqueras (2008: 457, 459), aunque sin profundizar en sus contenidos ni en el contexto personal y político, por más que este último autor atribuya a Fraga — particularmente a raíz del centenario de 1997- la conversión de Cánovas en memoria del PP (Piqueras, 2008: 517, 605). Penella (2009: 355) ni siquiera refiere el título de la conferencia. 
hermenéutica. Más allá del discurso conmemorativo, Fraga hizo recuento de la acción de gobierno y tradujo su propio estado de ánimo. Enseguida centró la cuestión: «la cavilación de nuestro pasado histórico puede consistir en un ejercicio erudito [...] al calor de las efemérides»; pero no, sus palabras estaban dictadas «desde nuestro presente y con una manifiesta voluntad de extraer de la glosa del descomunal empeño histórico de don Antonio Cánovas del Castillo [...] las claves más profundas que puedan resultarnos útiles, aquí y ahora, en el propósito de configurar un orden de convivencia civil, libre, plural, pacífico y estable» ${ }^{60}$. Toda una manifestación de uso político del pasado.

Fraga no se había identificado públicamente hasta 1976 con la figura de Cánovas. Fuera del conocimiento intelectual, es rara la mención expresa anterior $^{61}$, y no figura desde luego en los discursos y libros elaborados desde 1969 en el marco de su acción política. Ni siquiera en su obra más inmediata y programática, Un objetivo nacional. Cánovas no estaba en la cabeza de Fraga, aunque pudiera estarlo asociado a Fraga en la mente de alguno de sus colaboradores. Gabriel Cisneros había establecido a finales de 1975 el paralelismo describiendo al hombre que requería la política española: «un hombre con alcanzada visión nacional, con instinto del Estado mejor que con fervor partidario, capaz - como Cánovas - no solo de vertebrar las fuerzas propias, sino de propiciar la integración de las concurrentes, capaz de abordar los más audaces pactos y servir de eje para el más extenso e integrador de los compromisos históricos. Un hombre como Fraga» ${ }^{62}$.

Favorecida por el calendario, esa identificación pudo ser rápidamente interiorizada por Fraga a la vista de la parsimonia de Arias y la oposición percibida hacia sí mismo ${ }^{63}$. Tuvo algo de desahogo, pues tampoco Cánovas fue

60 Fraga (1976b: 9).

61 Véase Pániker (1969: 350), relativizando su propia salida del gobierno («A Cánovas no le importaba dejar de ser ministro e irse al Archivo de Simancas»). En 1951 Fraga realizó una reseña de las obras de Fernández Almagro y de García Escudero sobre Cánovas, publicadas aquel mismo año, esclarecedora para fijar su propia evolución. Allí se distancia del primer autor al considerar Fraga un "gran error histórico» de Cánovas su apuesta por la vigencia futura del liberalismo, mostrándose más próximo de Bismarck que del político malagueño, y parece coincidir con la tesis de la segunda obra negando la posibilidad de un liberalismo español (Fraga, 1951: 104, 106-107).

62 Prólogo a Milián (1975: 5-7). Milián, colaborador de Fraga, tampoco hace mención a Cánovas en su libro, aunque sí a Maeztu, quien según Fraga siempre se consideró «un hombre de centro» (Milián, 1975: 47, 57, 287, 343, 407).

63 Antes de aquella conferencia, hizo en las Cortes una referencia improvisada a Cánovas como referente del proyecto gubernamental de reforma, contraponiéndolo a Marcelo Caetano en Portugal (Informaciones, 23-24/01/1976). El discurso programático de 
nunca popular, «en el sentido fácil de la expresión». Fraga se veía como un nuevo Cánovas, doliente como él («pobre Antonio..., él solo llevaba la cruz de todos los españoles» $\left.{ }^{64}\right)$. Transida de una fuerte temporalidad, y más allá de su voluntad de representación del pasado, esta conferencia permite fijar la mente y el presente político de Fraga con mayor precisión que sus propias memorias, muy condicionadas por hechos posteriores. No sorprende que enseguida se acuñase el término de "canofraguismo»" ${ }^{65}$.

A juicio de Fraga, y a pesar de las notables diferencias existentes entre la España postfranquista y la de la Restauración, el problema político fundamental era el mismo: "cómo lograr un consenso amplio, apoyado en una organización institucional adecuada y flexible», para que los españoles de distintas ideas "puedan convivir pacíficamente, colaborar en empresas comunes, defender civilizadamente lo que les separa, alternar en el ejercicio del poder $y$, en definitiva, tolerarse mutuamente ${ }^{66}$. Las grandes líneas del proyecto canovista servían para coronar con éxito la «Segunda Restauración». Asimismo los caracteres del personaje histórico describían al nuevo artífice del proyecto: «de familia digna pero modesta, [...] estudiante brillantísimo, periodista eficaz, profesional reconocido, diplomático ocasional», «físicamente fuerte, trabajador incansable, dotes intelectuales de primer orden, y un sentido claro a la vez de la autoridad y de la dialéctica». Quien considerase la biografía de Fraga sabía que Cánovas no era el único que había llegado «a la gran tarea con un saber y un querer completos" ${ }^{67}$. Y con un plan reformista viable: una "reforma constitucional como compromiso de reconciliación», pese a «las incitaciones de los impacientes, las reservas de los puristas y el rechazo de los resentidos», señalaba. En ese proceso "los partidos políticos eran insoslayables», aunque prefería «dos grandes partidos como el sistema inglés», muy apreciado por Fraga como estudioso y observador privilegiado ${ }^{68}$.

Desde los tiempos londinenses pensaba que el juego entre una gran fuerza conservadora y un gran partido de izquierdas, leales ambos a la Monarquía, aseguraría la superación pacífica de la dictadura. Tras las expectativas frustradas del tardofranquismo, a él le correspondía construir ahora el futuro gran

Arias acabó siendo interpretado como una réplica a Fraga en favor del caetanismo ( $\mathrm{La}$ Región, 29/01/1976). En la conferencia posterior, "Continuidad y reforma», Cánovas no está y a quien menciona Fraga es a Maura y su fórmula de la revolución desde arriba (Fraga, 1976b: 158-159).

64 Fraga (1976b: 26).

$65 A b c, 6 / 06 / 1976$.

66 Fraga (1976b: 26).

67 La identificación resulta clara en el perfil autobiográfico de Fraga (1987: 247).

68 Las expresiones citadas en Fraga (1976b: 14, 17, 24 y 29; 1960). 
partido de centro derecha partiendo del embrión existente (GODSA), juzgaba Fraga, sin ser consciente de la fragmentación y ampliación del cuerpo social en curso. El Llamamiento para la Reforma Democrática (25 de febrero de 1976) fue bastante menos de lo quiso ser: ese núcleo central que pudiera aglutinar a otras muchas formaciones ${ }^{69}$, aplicando su vieja teoría del centro, que alcanzaba nuevo sentido transfigurado Fraga en Cánovas.

Surgirían inevitablemente otros grupos políticos con afán de protagonismo, ya fueran democristianos (Pidal y la Unión Católica dudaron también en sumarse al proyecto de Cánovas), liberales o conservadores. El límite estaba en los socialdemócratas. Personalmente, y como Cánovas, estaba dispuesto a aceptar en su partido incluso «a progres [...] sabiendo [...] que esta Monarquía no se puede afianzar más que con los desengañados y los arrepentidos ${ }^{70}$. Pero a la larga no tendrían sentido más de dos partidos. Como había ocurrido a finales del ochocientos, confiaba en que los nostálgicos del pasado acabarían integrándose en el sistema canofraguista, tal era la tarea histórica del nuevo partido conservador. Con el tiempo, en democracia, contemplaba, este gran partido llegaría desde la derecha hasta la izquierda del centro ${ }^{71}$.

\section{EN BUSCA DE UN SAGASTA}

Para reinventar el turnismo canovista, Fraga necesitaba un político aglutinador de las distintas fuerzas de izquierda moderada en otro gran partido leal a la monarquía. "Cánovas no hubiera podido realizar su obra si a ella no hubieran colaborado, con gran patriotismo y sentido de la realidad, Sagasta, Castelar y otros posibilistas». Debía encontrar también él a esa persona, aunque tuviera que enfrentarse «a la izquierda desmelenada y ausente de todo realismo» ${ }^{72}$.

El regreso de destacados miembros del exilio ofrecía una señal cierta de apertura del gobierno. La aparición en público autorizada de diversos grupos u organizaciones (EEDC, PSP, UGT) confirmaba la posibilidad de los partidos políticos, aunque Fraga no ocultó que la legalización no alcanzaría al Partido Comunista («podemos y debemos, como hicieron los alemanes en los

69 Fraga (1987: 61), Palomares (2006: 251-252) y Penella (2009: 311, 358-359, 371) confieren a los teóricos de GODSA y Reforma Democrática un carácter socialdemócrata o de centro izquierda, que no resulta conciliable con el discurso coetáneo de Fraga.

70 Fraga (1976b: 13).

71 La trayectoria del PP, sumando las herencias de AP y UCD, hará realidad esa aspiración de Fraga, aunque sacrificando su liderazgo.

72 Fraga (1976b: 12 y 23). 
años cuarenta y cincuenta, excluirlos de la transición y ponerlos en una razonable cuarentena; ellos verán los méritos que hacen para más adelante»), insistió en ello hasta su último día como ministro ${ }^{73}$, condenando a los comunistas a ser una fuerza extrasistema. El futuro entendimiento entre Suárez y Carrillo cambiará estas previsiones.

Descartados los comunistas, Fraga se había visto con el PSP, con los socialistas catalanes, con el líder del PSDE y los socialistas históricos de Llopis. Pero lo más significativo fue el contacto con el PSOE renovado de Felipe González y la velada propuesta que le hizo de reactualizar una especie de Pacto de El Pardo para establecer una alternancia pacífica. Sugirió que González podría no tardar en encabezar el gobierno, en «limpia competencia electoral», lo que significaría para Fraga la culminación de la Segunda Restauración, lo mismo que cien años antes había supuesto la llegada de Sagasta al poder ${ }^{74}$.

El silencio de los socialistas ante sus propuestas provocó su desahogo en la conferencia: "Yo he hecho todo lo que un hombre político puede hacer en el mando para atraer a la legalidad común a todos los hombres y facciones políticas que lo han deseado». Aun así, estaba dispuesto a recibir ataques (también «Cánovas tenía experiencias personales que le recordaban la escasa madurez ciudadana del país»), pero no permitiría que se jugara con la estabilidad del sistema. Como Cánovas, que "cuando alguien intentó volcar el tablero, como los anarquistas el 98 [sic], no vaciló en emplear la mano dura» ${ }^{75}$. Estas palabras - reverberando todavía hechos como los de Vitoria o la detención de los miembros de la Platajunta— no podían sino tener efectos devastadores.

$73 A b c, 2 / 07 / 1976$. La actitud contradictoria de Fraga ante el PCE, en Bernáldez (1985: 188-189).

74 Fraga trató de corregir las distintas versiones sobre la conversación: «se ha dicho que yo le dije a Felipe González que primero yo, y luego él; al contrario, le dije que mi éxito consistiría en crear un sistema político en el cual él pudiera llegar a ser presidente del Gobierno tal vez dentro de unos cinco años» (Fraga, 1987: 46). Según Raúl Morodo, Fraga había propuesto con anterioridad a Tierno Galván, líder del PSP, que representase el papel de Sagasta dentro de la obra neocanovista que se proponía realizar (Ben Ami, 1980: 297).

75 Fraga (1976b: 22-23). Cánovas fue asesinado en 1897. El error muestra que al pronunciar aquella conferencia Fraga estaba mucho más pendiente del escenario político actual que de fijar con precisión la obra o el pensamiento del personaje. La memoria fraguista de Cánovas es olvidadiza. 


\section{LA RELACIÓN CON EL REY}

La comparación con Cánovas resulta problemática para enfocar las relaciones con el Rey. Fraga no era el presidente, aunque aspiraba a serlo. Coincidía plenamente con Cánovas en que la monarquía era "la Constitución interna de España, la que resultaba de su manera de ser, de su historia y de su sociología». Pero había que engastar esa pieza esencial. Cánovas «siempre se llevó bien con Alfonso XII, supo hacerlo manteniendo el lugar que le correspondía como responsable de la dirección política del gobierno, sosteniendo su criterio" frente a las actuaciones a veces poco ponderadas del monarca. Así logró hacer de aquel joven príncipe, sin experiencia política, «el Rey Pacificador». Cánovas fue el maestro político de Alfonso XII estableciendo «un ajedrez político en el que se podía jugar y en el cual todas las piezas cubrían al rey». El presidente del Gobierno era el arquitecto del sistema, no el $\mathrm{Rey}^{76}$.

Y este fue quizá el error político más importante de Fraga: su valoración del Rey. Al igual que otros ministros del primer Gobierno de la monarquía, Fraga menospreció la madurez política del rey Juan Carlos, que quería ser, y era ya, el principal artífice de la Transición, consciente de que no solo se jugaba su propio futuro o el de la Corona, sino el porvenir de la nación. En consecuencia, quería conducir personalmente la reforma, sin aceptar tutelas ni censuras. Y en su mente, al margen del verdadero alcance del proyecto Fraga, cualquier avance pasaba a mediados de 1976 por la sustitución del presidente del gobierno ${ }^{77}$.

\section{LAS INTERFERENCIAS DE SUÁREZ Y FERNÁNDEZ-MIRANDA}

Fraga podía entender que el Rey no apoyara incondicionalmente la labor del gobierno. Lo que no comprendía era la continua falta de entusiasmo que mostraba ante sus iniciativas personales. Pudo comprobarlo ya cuando al regresar de Londres entregó al Rey un papel con «las propuestas de lo que yo pensaba que se debía hacer al iniciar ese periodo histórico que empezaba». Era un nuevo manifiesto de Sandhurst, aunque "lo cierto es que no las tuvo muy en cuenta» ${ }^{78}$. Desde aquel momento Fraga se debatió entre su deseo de estricta lealtad al Rey y su contrariedad por las trabas constantes que ponían a su proyecto hombres

76 Fraga (1976b: 16, 22).

77 Sánchez-Cuenca (2014: 25, 160) valora la tirantez de las relaciones del Rey con Arias como principal motivo del cese, pero obvia este punto en el caso de Fraga, quizá más importante para la suerte de la primera reforma.

78

Fraga (1987: 23). 
cercanos a don Juan Carlos. Desde los inicios de aquel gobierno, vio clara «la actitud de personas como Adolfo Suárez o Martín Villa [que] jugaban a la espera». Pero «lo más grave fue que este juego empezó pronto a ser apoyado por Torcuato Fernández-Miranda», escribió más tarde ${ }^{79}$.

Fraga imprimió su sello y cargaba con la responsabilidad política de la reforma, aunque no había tenido plena libertad de movimientos. A propuesta de Adolfo Suárez, se había constituido una Comisión Mixta compuesta por miembros del Gobierno y del Consejo Nacional (encabezada por Arias y con Suárez como vicepresidente, en su calidad de responsable del Movimiento), de la que era miembro nato el presidente de las Cortes, Fernández-Miranda. Era la misma fórmula que este había patrocinado años atrás para dejar en vía muerta el proyecto de asociaciones defendido por Fraga en 1969. Desde entonces, la pugna intelectual y política de ambos personajes por definir la evolución legal del régimen no cesó y acaba resultando central en el transcurso del primer gobierno de la monarquía.

Fernández-Miranda no creía en Arias, pero tampoco en las iniciativas de Fraga. La revitalización de dicha comisión le permitía no solo participar, sino tutelar la labor de gobierno. El debate de la Comisión, aunque apenas trascendiera, establecía diferencias entre dos proyectos políticos. Al oponerse a Fraga, latía sobre todo el propósito de evitar que Fraga acabara dando oxígeno al mortecino Arias. Fernández-Miranda actuaba como un celoso guardián del plan de la Corona haciendo la pinza con Suárez ${ }^{80}$. Sabían que debía irse de la

79 Fraga (1987: 25).

80 Bernáldez (1985: 163-164); Tusell (2003: 271-276, 319); Abella (2005: 80-82, 88); Herrero (2007: 108-110, 117-118); Ortí Bordás (2009: 218-222). Gallego (2008: 259-263, 301, 379-381) obvia la posición del Rey al valorar las motivaciones de Fernández-Miranda y Suárez contra Fraga en la Comisión Mixta, haciendo de Torcuato la auténtica variable independiente del proceso de reforma, y de Suárez un freno respecto a la actitud más reformista y decidida de Fraga. Sánchez-Cuenca (2014: 112, 165-167), al juzgar el cambio de actitud de Suárez en el verano de 1976, no descarta que el formato propuesto de Comisión Mixta no escondiese por su parte un propósito de sabotearla, aunque desvincula de esa estrategia a Fernández-Miranda y reduce las motivaciones de Suárez —en ese «llamativo viraje» de una posición «inmovilista» a otra "reformista»— a simple ambición y pragmatismo políticos. Sánchez-Cuenca ignora que ese formato lo había utilizado ya el presidente de las Cortes cuando fue ministro del Movimiento, con fines similares, y bien pudo sugerírselo a Suárez. Las reuniones de la Comisión transcurren entre febrero y abril de 1976. Su dinámica interna, en Navarro (2014: 85-111). Sobre los trabajos de la ponencia nombrada en el seno del Consejo Nacional del Movimiento para juzgar la reforma Arias-Fraga se ha detenido oportunamente Sánchez-Cuenca (2014: 
ley a la ley, pero sin miedo al desmantelamiento de unas instituciones que ya habían cumplido su papel. Una reforma parcial carecía de sentido y había que facilitar al Rey la elección del nuevo presidente ${ }^{81}$.

\section{CAMBIO DE REGISTRO: DE CÁNOVAS A MAURA}

Las distintas piezas del proyecto Fraga fueron llegando a las Cortes para su discusión, aunque al final no las principales ${ }^{82}$. El vicepresidente ni siquiera pudo defender en la Cámara el proyecto de Ley de Asociaciones, como deseaba. Lo hizo Suárez y fue un discurso memorable en defensa del pluralismo que atrajo toda la atención sobre el joven ministro ${ }^{83}$. La suerte de los diferentes proyectos legislativos concebidos por Fraga habían quedado vinculados a la del presidente Arias, y esta se encontraba ya echada. Las primeras declaraciones del Rey a Newsweek (26 de abril), mostrando la distancia abierta con el jefe del Gobierno, se remataban dos meses después con nuevas manifestaciones de la prensa estadounidense, forzando la dimisión ( 2 de julio de 1976) ${ }^{84}$.

136-152). El que Suárez juzgara con dureza las propuestas de modificación introducidas en esa ponencia por jóvenes reformistas cercanos a él como Eduardo Navarro, se entiende bien en el marco de esa estrategia, que no puede considerarse improvisada. Esas modificaciones mejoraban el proyecto Fraga cuando Arias ya estaba sentenciado, y no interesaba continuar por ese camino. También debe notarse que Navarro había figurado en GODSA.

81 Fernández-Miranda (1996: 158, 193, 228-229, 239-244); Herrero (2007: 120-123).

82 En el pleno del 25 de mayo fue aprobado el proyecto de Ley Reguladora del Derecho de Reunión. Respecto a los proyectos de Ley sobre Derecho de Asociación y Reforma del Código Penal, aunque el primero salió también adelante, en la práctica tuvo que ser aplazado ante las dificultades encontradas por el segundo. La Ley Electoral apenas quedó esbozada. Mientras que los dos proyectos de reforma constitucional —el que afectaba a la reforma de las Cortes y el relativo a la sucesión a la Corona - ni siquiera se llegaron a presentar. Los avatares en las Cortes de todos esos proyectos, en SánchezCuenca (2014: 121-135).

83 Ese discurso del 9 de junio de 1976, inmortalizado en algunas de sus frases («vamos sencillamente, señores procuradores, a quitarle dramatismo a nuestra política. Vamos a elevar a la categoría política de normal lo que a nivel de calle es simplemente normal») confirmó al Rey que Suárez era el mejor candidato posible para sustituir a Arias (véase Romero, 2002: 86-90).

84 Palomares desdobla en su estudio la actuación de Fraga como ministro de la Corona y lo que llama «la reforma fallida de Arias» (Palomares, 2006: 256-261), desvinculando así al vicepresidente político de cualquier responsabilidad en lo que de hecho fue su principal tarea de gobierno. Elorriaga (2014: 66-71) obvia igualmente esta hora de Fraga. El estudio de Tusell y Queipo de Llano sobre Arias es concluyente al respecto: 
La decisión del Rey suponía un no rotundo a Arias, no tanto a Fraga. El monarca había alentado algún aspecto del proyecto Fraga, como la Ley de Asociaciones, y no tenía suficientes apoyos como para prescindir de los más destacados aperturistas. Tras el nombramiento de Suárez, don Juan Carlos puso interés para que permanecieran en el nuevo ejecutivo. «El rey me llamó por teléfono a casa», recordará Fraga, instándole a que siguiera en el Gobierno. "Le manifesté la imposibilidad de continuar»" ${ }^{85}$. Si hasta aquí había revivido a Cánovas, ahora se identificó con Antonio Maura. Ya lo había invocado cuando tomó posesión de su Ministerio, y había aspirado a algo más ${ }^{86}$. En 1976, como en aquella otra crisis de 1913 que marcó la ruptura de Maura con el sistema de la Restauración, la historia parecía repetirse. Fraga recrea un momento que salta a sus ojos.

Maura había sido el «jefe indiscutible de la derecha civilizada de aquel tiempo», esa derecha a la que aspiraba Fraga. «Maura hubo de enfrentarse con la marginación y la exclusión injustificadas. Se le llamaba únicamente en las crisis, y luego se le despedía». Fraga expresa su propio dolor. Creía saber las claves de aquella historia: «una clase política que entendía la cosa pública como un juego frívolo de influencias y figuraciones, no supo entender ni aceptar al único hombre de Estado del que disponían». A la larga, «se le creó una leyenda de hombre duro, autoritario, intransigente; se logró persuadir al mismo Rey de que debía preferir hombres más fáciles o más cómodos» ${ }^{87}$. Fraga hablaba seguramente de sí mismo, trasladaba a la mente de Maura sus propios pensamientos, como un otro yo. Con todo, su sentido de la lealtad le impidió cerrar el argumento y dar la espalda a la Corona. Aunque el no se pronunció — «mi mujer... estimó que estuve demasiado tajante»—, no resonó en Palacio como un nuevo no de Maura ${ }^{88}$.

La decepción fue profunda. De aquellos tres mosqueteros, ni él ni Areilza habían aparecido en la terna decisiva. No habían sido ellos los hombres del rey.

la reforma no fue obra suya sino de Fraga, nunca tuvo un programa claro y asumió el de Fraga (Tusell, 2003: 298, 331, 336-338). Sánchez-Cuenca (2014: 111), por su parte, entiende que Fraga fue el primer impulsor de la reforma y a él se debe lo esencial del proyecto Arias. Para Penella (2009: 349), el freno de Arias condujo el proyecto de Fraga a una vía muerta.

85 Fraga (1987: 53).

86 Fraga, «Don Antonio Maura y el no de los políticos», $A b c, 13 / 12 / 1975$, en Fraga (1976b: 175-178).

87 Ibid.

88 Fraga (1987: 51-53). Cernuda (1997: 141) destaca la lealtad de Fraga hacia el Rey no secundando a Areilza, que intentó convencer a Garrigues y Fraga para escribir una carta conjunta al Rey y detener el nombramiento. 
Otros políticos reformistas, más desapercibidos pero exponentes de una nueva generación, la del propio rey Juan Carlos y que tendrá ahora otro referente principal, Suárez, fueron quienes conectaron realmente con la voluntad democratizadora de la Corona. El desencanto de Fraga se percibe al inicio de un nuevo libro, donde figuran los textos de Cánovas y Maura, que enseguida llenó las librerías. «Los libros, como las personas, tienen fecha de nacimiento», escribe en el prólogo ( 6 de julio), Suárez ya presidente: «iba a ser un balance de una etapa; se ha convertido en una rendición final de cuentas» ${ }^{89}$.

\section{EL DESENLACE: FRAGA Y LA IMAGEN DE LA «DERECHA SALVAJE»}

El nombramiento de Suárez trastorna sus planes. Fuera Fraga del Gobierno, el Libro Blanco para la Reforma Democrática, elaborado por GODSA, perdía buena parte de su sentido. De hecho, se publicó sin la parte fundamental, la política. Lo que había sido concebido como un programa para un partido de gobierno nacía muerto. Además, la presentación simultánea del Libro Blanco y del volumen sobre Cánovas y la Segunda Restauración ${ }^{90}$ - fortaleciendo la idea del canofraguismo cuando Suárez y Fernández-Miranda ya habían lanzado la nueva filosofía de la reforma - se vuelve contra las propuestas de Reforma Democrática, cuyo significado plenamente democrático se ha subrayado a veces en contraposición a Alianza Popular. Palomares juzga de esquizofrenia política el cambio súbito de Fraga desde posiciones centristas y progresistas a otras netamente derechistas y anticuadas ${ }^{91}$, lo que resulta excesivo, pues más que un giro radical a la derecha, lo que traduce la puesta en pie de AP es una básica continuidad político-ideológica.

Juliá ha subrayado la desconsideración del hecho biológico - la desaparición misma de Franco- en su planteamiento de reforma ${ }^{92}$, pero más importante fue su desenfoque del hecho sociológico. Aunque Fraga manifestó una inquietud teórica por la sociedad y la sociología, apelando desde los sesenta al incremento de las clases medias y a sus potencialidades de cambio, la lectura

89 Fraga (1976b: 5).

$90 Y a, 27 / 10 / 1976 ;$ Informaciones, 15/11/1976.

91 Palomares (2006: 35, 148, 248, 267-268, 284, 288, 359). El hecho es que desde Reforma Democrática (RD) se invocó el «progresismo conservador» atribuible a Cánovas y presente en Fraga como referente ideológico que justificaba, sin contradicción, la entrada de RD en AP. Penella (2009: 374, 387) anota, no obstante, el sacrificio de RD en aras del «gran proyecto de modernizar la derecha española». Según Elorriaga (2014: 80), «el giro de Fraga buscaba 'civilizar' a los sectores más recalcitrantes».

92 Juliá (2010: 236). 
política del fenómeno fue desacertada al identificar esa centralidad de las clases medias - base del centrismo político- con el franquismo sociológico. Su estrategia de cambio es la de «un desarrollo político entendido como cambio dirigido ${ }^{93}$ que acaba negando en la práctica la capacidad reflexiva y transformadora de la propia sociedad española, aunque no dejase de apelar a ella (a «sus fantásticas posibilidades creadoras para reconducir los rumbos de nuestro destino histórico») en la conferencia sobre Cánovas ${ }^{94}$.

Aun entendiendo el centro como mayoría sociológica, Fraga no llegó a percatarse del cambio de la sociedad española, que comienza a manifestarse después de 1975 como no lo había hecho durante el franquismo. En Gobernación, Fraga solo reparó en lo negativo de las movilizaciones sociales, a diferencia de Suárez, que supo interpretarlas variando sustancialmente la concepción de reforma y del centro político. La creación de AP responde al intento - de acuerdo con su análisis- de dar verdadero cuerpo político al franquismo sociológico (con el que sigue confundiendo en 1976 los deseos generalizados de orden y paz de las clases medias) como garantía futura de una gran fuerza conservadora. La escenificación pública de AP, dando entrada a nombres de todas las tendencias franquistas, tuvo el efecto contrario: si Fraga quería conectar con la opinión, se equivocó al concentrar alrededor suyo todo el antiguo sistema de representaciones colectivas ${ }^{95}$.

El giro de Fraga, presentándose junto a López Rodó y Silva, entre otros, al frente de AP, antes que como un giro radical ${ }^{96}$, puede ser entendido como un giro completo, un regreso al punto de partida de 1969. De la pretendida invención del centro, la escenificación de los Siete Magnificos — la figura de un franquismo histórico dispuesto a perdurar- facilitó que, en una rápida transmutación de sentido, se acabara identificando de forma injusta a Fraga con la imagen de la derecha salvaje o incivilizada, difícilmente conciliable con la idea de una mayoría natural, equilibrada y abierta, que había incorporado el

93 Discurso de Fraga de 28/04/1975 prolongando sus reflexiones de 1971-1972.

94 Fraga (1976b: 10).

95 Para Penella (2009: 381) vendría a ser una «alucinación» de la opinión publicada esa imagen de «la invencible armada neofranquista capitaneada por Manuel Fraga», perdiéndose de vista la "complejidad de la creación de Fraga».

96 Juliá (2010: 269) subraya cómo «con la izquierda en movimiento, a la derecha de Fraga, y sin haberse movido del centro, solo se abría un abismo", lo que explicaría el refugio en AP de antiguos adversarios suyos. Gallego (2008: 461) niega también ese supuesto giro del "centro" a la "derecha», una falsa impresión que beneficiaría a la imagen moderada y reformista del presidente Suárez. 
vocabulario de Fraga como sucedáneo de su teoría del centro, y que tardaría mucho tiempo en cuajar ${ }^{97}$.

\section{A MODO DE CONCLUSIÓN}

A comienzos de los setenta el joven Ignacio Camuñas — más tarde en UCD - calificaba el nuevo énfasis en el centro político como un «camuflaje de la derecha» (parafraseando a Duverger sin citarle). Aunque reconocía a Fraga un «aperturismo crítico» fijó entonces con claridad la posición centrista como aquella que tiene «a la derecha a todas las personas aperturistas del sistema y a la izquierda al socialismo democrático»" ${ }^{98}$. El mito de Fraga como padre del centro político ha perdurado, no obstante ${ }^{99}$. Su idea de centro encerraba una concepción conservadora de la sociedad que limitaba el alcance de la reforma —una evolución lenta y gradual que no rompía verdaderamente

97 En España, el término «derecha salvaje», sin duda peyorativo y que ha perdurado hasta la actualidad en el lenguaje político más combativo, parece arrancar — a falta de un estudio pormenorizado - de la izquierda intelectual vinculada a la revista Triunfo. Llena la portada del 29/01/1977 para referirse a la derecha asesina que había actuado los días anteriores en Madrid (calle de la Estrella y matanza de Atocha). La revista la oponía de manera explícita a la «derecha nacional enteramente respetable», que identificaba con Suárez. Desde su tribuna en El País (26/03/1977), Francisco Umbral, analizando con ironía el apartamiento de Areilza del primer Partido Popular, contrapuso el carácter de «derecha civilizada» que defendió aquel, con «la derecha salvaje, la de siempre» que el escritor asociaba a Fraga y los siete prohombres de AP. Apreciación injusta al existir coetáneamente una extrema derecha política y mediática (Fuerza Nueva, El Alcázar) de carácter reaccionario y golpista (Rodríguez Jiménez, 1994) con la que Fraga establece distancias. La imagen, añadiendo el epíteto de «catastrofista» al de salvaje, la esgrimió de manera abrupta e interesada Felipe González contra Fraga recién llegados los socialistas al poder $(A b c, 10 / 04 / 1983)$, expandiéndose con éxito, aunque resulte paradójico, pues fue Fraga en todo caso quien pudo domesticar a la derecha salvaje como un servicio a la democracia. La obra de Penella (2005) haciendo del primer Partido Popular el origen de AP, incurre en un anacronismo, tal vez con la intención de contrarrestar esa imagen peyorativa volcada sobre Fraga. El primer PP se sitúa en los orígenes de UCD, no de AP: solo retrospectivamente puede vinculársele con la formación de Fraga. La presencia de Areilza y Osorio al lado de Fraga en las elecciones de 1979 implica otro giro, en sentido opuesto al anterior, a partir del centro que define Suárez y explica los movimientos de los demás.

99 Alonso-Castrillo (1996: 64, 90); Baón (2001); Penella (2009: 385). 
con las instituciones franquistas-, al condensar, en fin, un régimen de historicidad $^{100}$ donde el futuro queda sometido al imperativo de un presente esencialmente marcado por la fuerza del pasado.

Para Fraga la futurología era una frivolidad. «El futuro es el presente mismo al que hemos llegado con retraso» ${ }^{101}$. «¿Qué España es la que va a proyectarse en el futuro?», se preguntaba. «No puede ser más que la España actual, sociológicamente hablando». "¿Con sus instituciones? Esta es otra cuestión, pero también forman parte del inventario», añade ${ }^{102}$. Esta reflexión en el minuto final del franquismo y dirigida no tanto a alentar el cambio como a alertar contra el «cambio incontrolable» ${ }^{103}$, le acompañó durante la Transición como un freno de la historia. Esa expresión subyace en el lenguaje introducido poco después por Morlino para explicar el cambio político, valorando la dificultad intrínseca de un cambio orientado, fiel a la mente de quienes lo dirigen, en el marco de los procesos de desarrollo y modernización, donde la voluntad de elección es insoslayable ${ }^{104}$. El continuista avanzado que fue Fraga, pretendió una continuidad imposible $e^{105}$, en contraste con la actitud del Rey y de Suárez, mucho más decidida y henchida de coraje. El olvido del pasado fue un requisito para inventar el futuro: el nuevo proyecto de convivencia, en el sentir de Suárez ${ }^{106}$, que exigía no solo un nuevo sistema político que dejara realmente atrás al anterior, sino un nuevo régimen de historicidad.

En ese sentido, la apelación al canovismo por parte de Fraga fue un claro error. Su visión del pasado obviaba la primera España democrática, la Segunda

${ }^{100}$ En el sentido de Hartog (2003), quien entiende por regímenes de historicidad los diferentes modos de articulación de pasado, presente y futuro. Según se ponga el acento principal en una categoría u otra, el orden del tiempo no es, en efecto, el mismo.

101 Fraga (1973: 19, 37).

102 Fraga (1976: 62).

103 Ibid.

${ }^{104}$ Morlino (1985: 55-56). En la tipología del autor, el cambio orientado/no orientado, al que denomina también normativo/no normativo o teleológico/no teleológico, atañe fundamentalmente a la dirección consciente y deliberada, o no, del mismo, y a la determinación de los fines y valores en la transformación del sistema. Una pretensión que escapa a la misma dinámica de modernización, pues «existen siempre cambios no queridos, no previstos, y que no se consiguen controlar completamente», señala el autor. El cambio no orientado o desorientado se identifica a la postre con el cambio incontrolable, de manera clara en la mente de Fraga.

105 Esas dos expresiones en Penella (2009: 301) y Tusell (2003: 347), respectivamente.

106 Le Point, 4/10/1976. El mañana no escrito al que había aludido con Machado en su discurso de 9 de junio de 1976. 
República, yendo mucho más atrás, a los orígenes de la Restauración, donde aparentemente pretendía basarse para proceder a un simple proyecto de rehabilitación de las instituciones franquistas, no a su derribo, aunque este pudiera realizarse desde dentro del viejo edificio político todavía en pie, en una arriesgada obra de ingeniería política, como demostraría Suárez a continuación, llenando de inmediato sentido democrático la política reformista. Fraga, que no admitió posibles errores cometidos, lejos de reconocer en Suárez acierto alguno, siempre le tuvo como el gran culpable de su fracaso ${ }^{107}$.

Pero es preciso aún notar que el mito de Cánovas asociado a Fraga es una creación posterior a su fracaso político y que vino a encubrir las principales razones del mismo: la indefinición de su proyecto reformista, su pérdida de sintonía con el cambio social o las dificultades encontradas en su relación con el Rey, como reverso de algo más fundamental y mantenido en el tiempo: su miedo al cambio incontrolable. Fuera de la primera mención de Cisneros finalizando 1975, o de la buscada publicidad de su conferencia sobre Canovas al salir del Gobierno en 1976, son nombres próximos a Fraga quienes desde los años ochenta van a construir historiográficamente esa identificación con objeto de enaltecer la figura de Fraga entre los grandes del conservadurismo español ${ }^{108}$, por más que ese empeño acabe convirtiendo lo que fue un fracaso relativo o transitorio, en un error axiomático.

\section{Bibliografía}

Abella, C. (2006). Adolfo Suárez. Madrid: Espasa.

Alonso-Castrillo, S. (1996). La apuesta del centro. Madrid: Alianza.

Baón, R. (2001). Historia del Partido Popular. Madrid: Espasa-Calpe.

Ben Ami, S. (1980). La revolución desde arriba. Barcelona: Riopedras.

107 «El gran culpable fue Suárez», entrevista a Fraga, 20/02/1987, en Jáuregui (1987: 15). Penella (2009: 379-380) traslada esa misma convicción de que no hubo error alguno por parte de Fraga.

108 Véase particularmente García Escudero (1988: 19-20, 285-286, 293-295): «QQuién será el Cánovas de la futura Restauración? Se lo preguntaba Cambó el 13 de noviembre de 1937. En la España de 1975 no parecía posible la duda. ¿Quién no adivinaba en Manuel Fraga al Cánovas del inminente futuro, al hombre mejor preparado para la difícil conciliación de apertura y autoridad, libertad y firmeza, cuando, como el propio Fraga ha escrito, tantos cabos sueltos quedaban después de la muerte de Franco, 'con tan poco realmente atado y, sobre todo, bien atado'?», afirma de manera retórica y categórica el autor (p. 295), antiguo colaborador de Fraga en el Ministerio de Información, sin aportar datos de esa supuesta identificación general: ni siquiera la conferencia conmemorativa de Fraga sobre Cánovas. 
Bernáldez, J. M. (1985). El patrón de la derecha. Barcelona: Plaza y Janés.

Calvo Serer, R. (1968). España ante la libertad, la democracia y el progreso. Madrid: Guadiana. Cebrián, J. L. (1980). La España que bosteza. Madrid: Taurus.

Cernuda, P. (1997). Ciclón Fraga. Madrid: Temas de Hoy.

Díaz, O. y Meer, F. (2010). Rafael Calvo Serer: la búsqueda de la libertad (1954-1988). Madrid: Rialp.

Elorriaga, G. (2014). Fraga y el eje de la transición. Madrid: Congreso de los Diputados.

Fernández-Miranda, P. y A. (1996). Lo que el rey me ha pedido. Barcelona: Plaza y Janés.

Fraga, M. (1951). Cánovas, 1951. Cuadernos Hispanoamericanos, 22, 103-108.

— (1960). El Parlamento británico: desde la 'Parliament Act' de 1911. Madrid: Instituto de Estudios Políticos.

- (1972). El desarrollo politico. Barcelona: Grijalbo.

— (1973). Legitimidad y representación. Barcelona: Grijalbo.

_ (1973b). La República. Barcelona: Planeta.

- (1975). Las Leyes. Barcelona: Planeta.

— (1976). Un objetivo nacional. Barcelona: Dirosa.

- (1976b). Cánovas, Maeztu y otros discursos de la segunda Restauración. Madrid: Organización Sala Editorial.

- (1980). Memoria breve de una vida pública. Barcelona: Planeta.

— (1987). En busca del tiempo servido. Barcelona: Planeta.

Fuentes, J. F. (2011). Adolfo Suárez. Biografía política. Barcelona: Planeta.

Gallego, F. (2008). El mito de la Transición. La crisis del franquismo y los origenes de la democracia, 1973-1977. Barcelona: Crítica.

García Escudero, J. M. (1988). Vista a la derecha. Cánovas, Maura, Cambó, Gil Robles, López Rodó, Fraga. Madrid: Rialp.

Gilmour, J. (1999). Manuel Fraga Iribarne and the rebirth of Spanish conservatism, 1939-1990. Lewiston: Edwin Mellen.

Hartog, F. (2003). Régimes d'historicité. Paris: Seuil.

Herrero, L. (2007). Los que le llamábamos Adolfo. Madrid: Esfera de los Libros.

Hispán, P. (2006). La política en el régimen de Franco entre 1957 y 1969. Madrid: Centro de Estudios Políticos y Constitucionales.

Iglesias de Ussel, J. (2012). Manuel Fraga, sociólogo. Cuadernos de Pensamiento Político, octdic., 151-169.

Jáuregui, F. (1987). La derecha después de Fraga. Madrid: El País.

Jiménez Blanco, J. (1978). De Franco a las elecciones generales. Madrid: Tecnos.

Juliá, S. (2010). Hoy no es ayer. Barcelona: RBA.

López Nieto, L. (1988). Alianza Popular: Estructura y evolución electoral de un partido conservador, 1976-1982. Madrid: Siglo XXI.

López Rodó, L. (1993). Claves de la Transición. Barcelona: Plaza y Janés.

Luca, G. (2001). Fraga, retrato de un fascista. Miatzen SARL.

Mateos, A. y Soto, A. (2005). El franquismo, 1959-1975. Madrid: Arlanza.

Milián, M. (1975). Fraga. Retrato en tres tiempos. Madrid: Dirosa.

Morán, G. (1979). Adolfo Suárez. Historia de una ambición. Barcelona: Planeta. 
Morlino, L. (1985). Cómo cambian los regímenes políticos. Madrid: Centro de Estudios Constitucionales.

Navarro, E. (2014). La sombra de Suárez. Barcelona: Plaza y Janés.

Ortí Bordás, J. M. (2009). La Transición desde dentro. Barcelona: Planeta.

Palomares, C. (2006). Sobrevivir después de Franco. Evolución y triunfo del reformismo, 19641977. Madrid: Alianza.

Pániker, S. (1969). Conversaciones en Madrid. Barcelona: Kairós.

Penella, M. (2005). Los orígenes y la evolución del Partido Popular: una historia de AP: $1973-$ 1989. Salamanca: Caja Duero.

- (2009). Manuel Fraga Iribarne y su tiempo. Barcelona: Planeta.

Piqueras, J. A. (2008). Cánovas y la derecha española. Barcelona: Península.

Powell, Ch. (2007). El reformismo centrista y la Transición democrática. Historia y Política, $18,49-82$.

Rodríguez Jiménez, J. L. (1994). Reaccionarios y golpistas. La extrema derecha en España (19671982). Madrid: CSIC.

Romero, A. (2002). Historia de Carmen. Barcelona: Planeta.

Romero, E. (1973). Cartas al Rey. Barcelona: Planeta.

Sánchez-Cuenca, I. (2014). Atado y mal atado. El suicidio institucional del franquismo y el surgimiento de la democracia. Madrid: Alianza.

Tusell, J. y Queipo de Llano, G. (2003). Tiempo de incertidumbre: Carlos Arias Navarro entre el franquismo y la transición. Barcelona: Crítica. 
